\title{
Research on Computer Digital Means of Film post-production
}

\author{
Xiao Han \\ Chongqing College of Electronic Engineering, University Town, Shapingba District, Chongqing, P. R. China
}

84865814@qq.com

Keywords: Film Digital Technology, Art Production, Post-production

\begin{abstract}
Film is the product of human scientific and technological progress, and film technology innovation is the inevitable result of scientific and technological progress. Computer digital production technology can bring this revolution in the film, a great boost to the development of the film industry. Now the digital film has become the main means of making the film, its significance lies in improving the visual arts, creating the screen wonders. Facts have proved that digital film production into the development of the film into the fresh blood, creating a number of screen miracles, which has become an inevitable trend. With the rapid development of computer technology and the increasing possibility of art and the participation of more filmmakers, in the interaction and evolution of technology and art, hi-tech will be more and more rational to achieve with the reconstruction of the film art.
\end{abstract}

\section{Theoretical Introduction of Digital Technology}

Film Digital Technology Film is the product of technological progress, the development of the film from the traditional, but different from the traditional film, the audience more and more immersed in the digital technology film visual wonders. Digital technology The biggest difference between cinema and tradition is that it will use the film as the carrier for images that can be edited using a computer to process digital information technology and compute and synthesize the film through the use of authoritative software. But the film's digital technology is not complete, filming and screening of film production, production, still need to use some of the traditional film production process, the screening still need to film as the carrier.

The emergence of digital new media constantly challenges and enriches the form of communication of image technology in the visual culture era. It has many new features, which scholars call "revolutionary" image. The application of new media to extend the visual style, not only brings a new visual experience, but also on people's mental state, value orientation, aesthetic awareness, space and time feeling. Digital technology has now reached another peak, such as the use of graphics workstations and some well-known graphics software, modeling and rendering technology can be used to create a very realistic particle, digital film will fundamentally change the characteristics of this form of media to digital cinema The form will no longer be a reflection of reality, but create a virtual space ${ }^{[1]}$.

Computer generated images, also known as computer graphics and computer imaging technology. People use computer software from the establishment of the digital model until the video generated by the required dynamic picture, in the whole process can completely without the participation of the camera. Due to the involvement of digital technology, video editing and editing will be much easier, and even an interaction with the audience, the audience can control the film, the film digital advertising to break it. The physical boundaries between the Internet and video games, the emergence of movies, on-demand movies and video games will be more popular in the future. The development of digital image technology not only allows us to enter a new space, but also prompted the audience to participate in a way of change, from one-way broadcast to two-way interaction, achieve true sense of the spread. 


\section{Advantages of Digital Technology}

Digital technology can be said that the impact of film art, from the film production process, the preparation of the script, pre-photographed before pre-visualization, post-production digital image synthesis and other links, can see digital technology "figure. Digital technology has a great influence on the performance means, skills, film themes, film acceptance channels, movie viewing psychology, movie aesthetic value judgments and so on ${ }^{[2]}$. Fig.1 shows advantages analysis of digital technology.

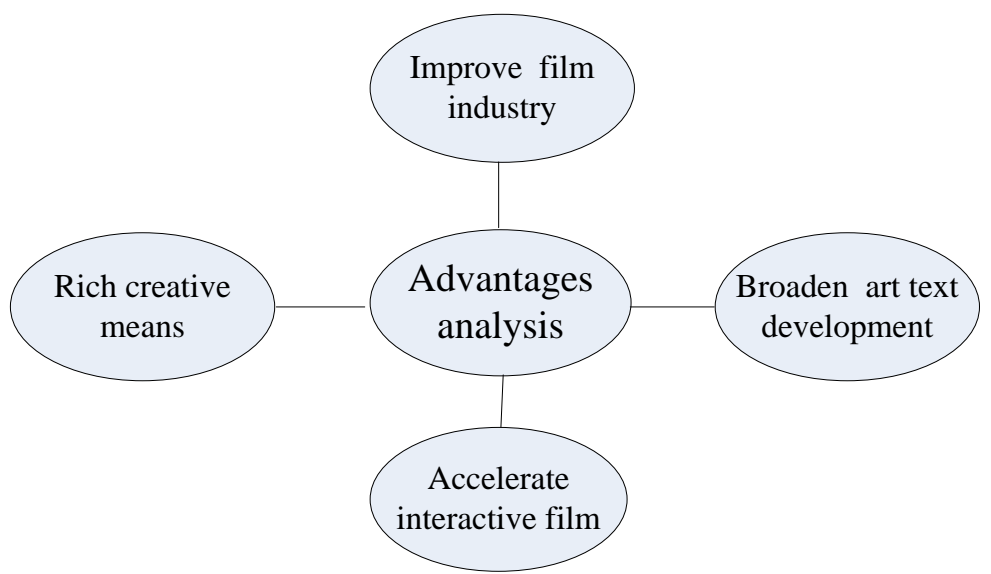

Fig.1. Advantages analysis of digital technology

With the development of the times, film art needs to change rapidly to keep up with the rapid development of the times. Because of the changes in the times we live, people's thinking is developing so fast. The traditional film-recording and picture-drawing methods restrict the expansion of screen-viewing thinking, which is far from satisfying the requirements of artists. Digital technology is to break the carrier as the main basis to divide the division of film and television art. In the digital realm, the movie screen and the television picture all become the data file which exists in the computer, its essence is same, as processing method is also identical. For now, the two post-production process methods can also be applied to the production of television programs, such as digital special effects, three-dimensional animation, the film's latest achievements to television, so that Film and television workers have more and more common language, film and television first in the field of digital post-production came together.

Digital technology and scientific concept of the rapid development of science fiction film to enhance the aesthetic value, so as to the film industry continues to bring new vitality and huge economic benefits. Science fiction in the dissemination and promotion of scientific concepts were great value of science, so it has aroused great concern and thinking. Digital technology makes the film creators be the liberation of the imagination of the technology, the sci-fi world, the disaster scene, the three-dimensional animation has become an important object of film text performance. Digital technology involved in film creation, science fiction film established itself in the mainstream film in a solid position, the type of disaster film was born, and cartoon is developed into a mainstream film. The advent of digital cinema has given the film market a new dimension: technological progress creates new products that meet or augment the immediate needs of new demands, and secondly, technological advancement increases labor productivity. Technological progress changes the entire economic growth, but also indirectly affected the industrial structure changes.

\section{The Application of Film Digital Technology}

Based on the computer digital non-linear editing technology is mature, so that the latter part of the film and television editing tools have been greatly developed. This technology will be material to the computer, the use of computer editing. It uses the nonlinear mode of the movie clip, but the operation with the mouse and keyboard operation instead of scissors and paste manual operation, 
the clip results can be immediately playback, greatly improving the efficiency, and do not have to bear the loss of film and signal. At the same time it not only can provide all kinds of editing machine special effects ${ }^{[3]}$.

With the rapid development of film and television digital technology, post-production not only quickly completed the basic editing of the film, but also shoulder a very important special effects lens production responsibility. Special effects lens is shooting can't directly get the lens. Most of the early film and television stunts through model making, special photography, optical synthesis and other traditional means to complete, mainly in the filming stage and the printing process to complete. Risk and investment are often huge, the use of computer digital technology for special effects produced more and better means to greatly improve the special effect of post-production work. Digital synthesis technology, digital television technology in more and more widely today, as one of the independent application of technology in film and television production, and its role in no less than three-dimensional animation computer technology, digital synthesis technology is the most widely used in modern film and television production Of digital technology.

Digital synthesis technology, relative to the traditional synthesis technology, is mainly the use of advanced computer image theory and methods, a variety of source material collected into the computer inside, and computer mixed into a single composite image. The power of digital compositing is to combine two or more source images into a single image by various operations. This process contains many technical means, there are many artistic aspects of the selection, so a competent synthesizer for the synthesis process in technology and art have a more in-depth understanding. Because the ultimate goal of synthetic images is to allow viewers to watch, and people for the realism of the screen have the ability to identify the powder instinct. Digital video synthesis technology relies on a variety of powerful digital tools, including hardware and software in two ways ${ }^{[4]}$.

\section{Digital Processing of Film Post - production}

Digital technology in film production is the most significant contribution in the field of post-production, mainly in the following: digital special effects take the use of computer processing digital audio and video signals after the method to achieve visual and auditory special effects. Here is the main computer to deal with the image. There are two main types of computer-aided imaging technology: computer image processing and computer image generation. Currently the main two-dimensional, the main function of the image is simple to complex processing, including image synthesis. Such as the actors for dangerous action when the security zone; make special shapes, such as the nature of the animals have disappeared, such as the nature of the image, we can create a special atmosphere of the atmosphere, such as explosions, tornadoes, flooding, earthquakes, volcanic eruptions and so on. Fig.2 shows digital technology special effects processing pictures.
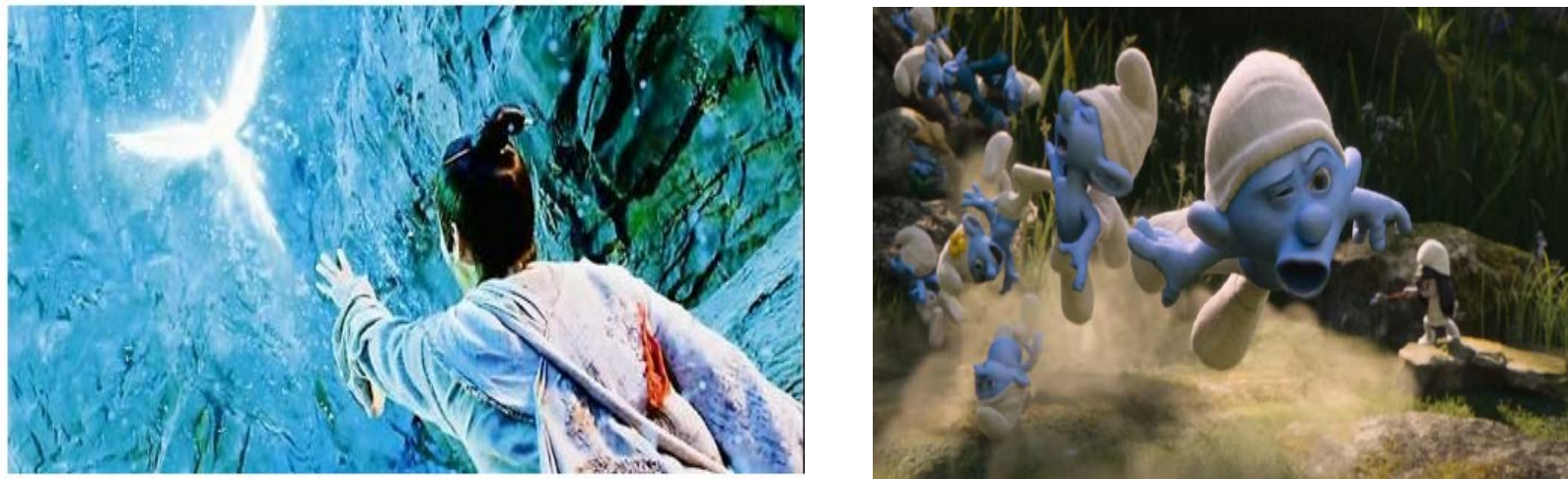

Fig.2. Digital technology special effects processing pictures

Image synthesis is one of the outstanding advantages of the computer, in the United States in recent years, the film has been widely used. In theory, the level of computer synthesis can reach infinite. Therefore, it can achieve the level and complexity of traditional technology can not be compared, and because the computer convenient, fast, simple features, its advantages have been 
making it more and more artists used. Computer image generation mainly refers to the computer-generated and generated images, including computer images, three-dimensional animation and motion sensing. The staff gathers a variety of movements through motion sensing equipment. The film can be seen everywhere in the figures figure - anchor when the boat waved goodbye to the crowd, sailing in the deck on the deck of the passengers, wreck from the height of falling people and so on. The powerful and special function of computer processing images, together with the shooting of real and traditional special effects, can create any effect that the artist can imagine ${ }^{[5]}$.

When using the computer platform for digital non-linear editing, the first shot of digital material, input to the computer's hard disk memory. Grouping, moving, pruning, covering all the lens material, by determining the in or out point, edit the material into a number of material segments, and named, good material, you can use the mouse to any access, into a required length of the edited clips. Digital non-linear editing convenient, accurate, free, fast, to the artist has brought unprecedented freedom of creation, to maximize the elimination of the film art of regret, creating a new epoch-making film clips, making it more and more Director and editor of the favor. Digital non-linear editing also provides a large number of scene transition, filter effects and other skills, can be completed during the video editing process to preview and modify. With the development of network technology, some film material can be shared.

\section{Conclusions}

Digital technology makes the film creators be the liberation of the imagination of the technology, the sci-fi world, the disaster scene, the three-dimensional animation has become an important object of film text performance. Film is no longer a century ago, a novelty of the invention, but has grown into a perfect art form and a powerful means of expression of the digital technology circle involved in film creation, so science fiction film established in the mainstream film of the solid position, animation is developed into a mainstream film. At the same time, digital images have also brought the film a true aesthetic update, through the magic of digital technology processing, film images as a "true lie." In the field of film aesthetics, digital technology makes the film language is facing reorganization, the film audience has been a more active aesthetic state. Digital technology in the film industry to bring a revolutionary impact, but also brought us endless thinking.

\section{References}

[1] GRIMSHAW ANNA. Teaching Visual Anthropology: Note from the field [J]. Journal of anthropology, 2010 (66): 237-258.

[2] PAUL HENLEY. Putting Film To Work: Observational Cinema as Practical Ethnography [J] .Working Images: Visual Research and Representation in Ethnography, 2014 (9):110-130.

[3] Fabe Marilyn. Watched films technique. California University of Press an introduction to the art of narrative film, 2014, 02.

[4] Ghanian Thomas. Digital Filmmaking: The Changing Art and Craft of Making Motoring Pictures. Focal Press, 2015, 05.

[5] Ostrow Saul .Point of View: An Anthology of the Moving Image. Bomb no96, 2016, 01. 